\title{
Miositis aguda postinfecciosa.
}

\author{
Acute post infection myositis
}

\section{Tori Tori Carlos*}

* Pediatra, Clínica Médica Ambulatoria, Universidad Peruana Cayetano Heredia, Clínica San Felipe. Lima - Perú.

\section{SUMMARY}

A seven year old patient in described with acute focal myositis, following an influenza-like infection, involving exclusively the gastroenemius and soleus muscles. The patient improved only with bed rest and symptomatic treatment and made a full recovery in three days. Laboratory studies showed a normal white blood count with an increase in the band forms, elevated SGOT, DHL, and CPK, all of which returned to normal after one week. The patient remains asymptomatic one month after his discharge.

KEY WORDS: Acute post-infection myositis, myositis,

\section{INTRODUCCION}

Se presenta un caso de miositis aguda focal transitoria, postinfecciosa, de etiología probablemente viral, en un niño de 7 años de edad, con dolor intenso en ambas pantorrillas, imposibilitándolo de mover las piernas y caminar.

El objetivo de la presente comunicación es llamar la atención sobre la presencia de la asociación de miositis transitoria aguda e infecciones virales principalmente el virus de la influenza.

\section{Caso clínico}

C.J.L., varón, de 7 años de edad, con antecedentes de hiperreactividad bronquial. Cuatro días antes de su ingreso había estado medicado con dicloxacilina y acetaminofén por un cuadro infeccioso respiratorio alto, caracterizado por fiebre, malestar general, coriza y tos. Siete horas antes de hospitalizarse, despierta con dolor intenso en ambas pantorrillas que le impedía mantenerse de pie y caminar

El paciente estaba febril pero en buen estado general, con tos irritativa y con un dolor exquisito en ambas pantorrillas, tanto espontáneo como a la palpación. El tímpano derecho estaba congestivo. La faringe presentaba congestión sin exudados. Al examen pulmonar se encontró sibilantes y roncantes escasos en campos pulmonares. El abdomen era blando, 
depresible e indoloro. No había hepatomegalia ni esplenomegalia y los genitales eran normales.

El examen neurológico mostró un paciente con estado de conciencia y pares craneales normales, reflejos osteotendinosos normales, salvo los aquilianos que estaban desminuidos. La motilidad activa estaba conservada en todos los miembros, pero disminuída a la flexión tanto ventral como dorsal de ambos pies por dolor y turgencia en ambas pantorrillas lo que hacía también difícil evaluar la fuerza muscular. En ambas regiones gemerales se encontró hiperalgia a la palpación.

No había cambios de temperatura de la piel, tumoraciones, edema, ni signos inflamatorios en ambas piernas.

En paciente estuvo en cama, tomando aspirina $325 \mathrm{mg}$ cada 6 horas condicional a dolor o fiebre, no recibiendo antibióticos. Al día siguiente su temperatura máxima fue de $38.3^{\circ} \mathrm{C} \mathrm{y}$ presentó tos productiva. La faringe seguía congestivo y sin exudado. Tenía escasos sibilantes y roncantes en ambos campos pulmonares. Había una marcada mejoría en cuanto al dolor de ambas pantorrillas, tanto espontáneo como a la palpación, pero continuaba sin poder mantenerse de pie y caminar.

A las 48 horas su temperatura fue menor de $37.3^{\circ} \mathrm{C}$. había muy poco dolor en las pantorrillas, la fuerza muscular en miembros inferiores estaba recuperándose y podía caminar con ayuda.

Exámenes auxiliares. Leucocitos: $7600 / \mathrm{mm}^{3}$, abastonados $13 \%$, segmentados $56 \%$, linfocitos $26 \%$, monolitos $5 \%$, hematíes $4^{\prime} 850,000 / \mathrm{mm}^{3}$, hemoglobina $12.9 \mathrm{gr} / \mathrm{dl}$, hematocrito $37.8 \%$, recuento de plaquetas $261,000 / \mathrm{mm}^{3}$. Velocidad de sedimentación $28 \mathrm{~mm} / \mathrm{h}$. Aglutinaciones negativas. Electrolitos: sodio $142.4 \mathrm{mEq} / \mathrm{L}$, potasio $4.24 \mathrm{mEq} / \mathrm{L}$, cloro $110.4 \mathrm{mEq} / \mathrm{L}$. Urea 24 $\mathrm{mg} / \mathrm{dl}$; creatinina $0.6 \mathrm{mg} / \mathrm{dl}$. Transaminasa pirúvica $34 \mathrm{UI} / \mathrm{L}$ (Normal: $0.40 \mathrm{UI} / \mathrm{L}$ ), transaminasa oxalecética (SGOT) $130 \mathrm{UI} / \mathrm{L}$ (Normal: 0-40 UI/L), dehidrogenasa láctica (DHL) 359 U (Normal: 90-285), creatinofosfoquinasa (CPK) 3376 UI/L (Normal: 60-218 UI/L). Examen de orina normal; no había hemoglobinuria. La radiografía de tórax era normal. Electrocardiograma: Bloqueo incompleto de rama derecha. En otros aspectos no se observan anormalidades.

Al día siguiente la dehidrogenasa láctica estaba en $471 \mathrm{U}$, la creatinofosfoquinasa en 15,520 $\mathrm{UI} / \mathrm{L}$, y la aldolasa en $8.2 \mathrm{U}$ (Normal: 3.0 a $10.0 \mathrm{U}$ ). La inmunoglobulina A $96 \mathrm{mg} / \mathrm{dl}$ (Normal: 60-290 mg/dl); IgG $1239 \mathrm{mg} / \mathrm{dl}$ (Normal: 650-1550 mg/dl); IgM 108mg/dl (Normal: $60-290 \mathrm{mg} / \mathrm{dl}$ ). Las proteínas totales estaban en $6.75 \mathrm{gr} / \mathrm{dl}$ (Normal: 6.0-8.1 gr/dl); albúminica en $3.71 \mathrm{gr} / \mathrm{dl}$ (Normal: $305-5.2 \mathrm{gr} / \mathrm{dl}$ ): alfa 1 globulina en $0.25 \mathrm{gr} / \mathrm{dl}$ (Normal: $0.15-0.40 \mathrm{gr} / \mathrm{dl}$ ), alfa 2 globulina en $0.81 \mathrm{gr} / \mathrm{dl}$ (Normal : $0.50-1.05$ ), beta globulina en 0.60 gr/dl (Normal: 0.55-1.20); gamma globulina $1.35 \mathrm{gr} / \mathrm{dl}$ (Normal: 0.60-1.60 gr/dl).

A la semana de alta fue examinado nuevamente, estaba afebril y asintomático; había vuelto a sus actividad es normales. La creatinofosfoquinasa estaba en $253 \mathrm{UI} / \mathrm{L}$. Un mes después del alta el paciente se encontraba asintomático.

\section{DISCUSION}

Las mialgias, especialmente de miembros inferiores y de la espalda son comunes en infecciones virales como la influenza. Estos malestares ocurren inmediatamente antes o al inicio de las manifestaciones respiratorias. Sin embargo, en este paciente como en otros 
reportados (1), el compromiso muscular usualmente se presentó cuando los signos y síntomas respiratorios estaban mejorando o ya habían pasado. El dolor era generalmente simétrico e incapacitante y se iniciaba después de un período de reposo. Es por eso que la mayoría de pacientes presentó el dolor al levantarse en la mañana o después de la siesta. Al examen tenían hiperalgia y algunos edemas de los músculos de la pantorrilla. Los pies los mantenía en flexión plantar. Intentar la dorsiflexión era doloroso y la fuerza muscular era difícil de evaluar por el dolor, que duraba entre 1 y 5 días. Los músculos de los miembros superiores y del tronco no estaban afectados.

En nuestro país se han publicado tres casos similares en pacientes pediátricos con miositis aguda focal, el año 1986 (2).

A las miositis focales se les ha descrito como pseudotromboflebitis $(4,5,6)$. Pueden permanecer como lesiones focales o derivar en polimiositis (6). Se puede localizar en la pared torácica (7), párpados (8), muslos (5), músculo temporal (9), músculo esternocleidomastoideo, o como una masa tumoral en el cuello (10). Toda esta sintomatología obliga a considerar en el diagnóstico diferencial a la dermatomiositis, polimiositis, tumores, sindrome de Guillain-Barré y ataxia cerebelosa (11).

En las biopsias musculares de estos pacientes se describen desde el edema con vacuolización focal e inflamación mínima de la fibra muscular (12), hasta la necrosis muscular con reacción inflamatoria, principalmente polimorfonuclear e infiltración perivascular (13), como también cambios degenerativos inespecíficos (14). La ausencia de infiltrados inflamatorios en las biopsias musculares no excluye la existencia de una miopía de tipo inflamatorio (15).

Los exámenes auxiliares muestras cifras de glóbulos blancos con valores bajos o normales. La transaminasa oxalacética está aumentada al igual que la dehidrogenasa láctica. La creatinofosfoquinasa (CPK) se eleva hasta en diez veces sus valores normales, alcanzando en nuestro paciente un valor 70 veces lo normal. Las elevaciones séricas de CPK son relativamente específicas para procesos miosíticos o distróficos del músculo estriado (esquelético o miocárdico) $(1,16)$. Aunque se han descrito alteraciones tóxicas e inflamatorias agudas en el miocardio en casos fatales de influenza (17), no se encontró evidencia de ello en nuestro paciente. Es por eso los niveles tan altos de CPK encontrados muy probablemente sean debidos al daño del músculo esquelético de los miembros inferiores. Niveles séricos del nivel encontrado en este paciente se ven en casos de distrofia muscular tipo Duchenne (1).

Se ha sugerido la posibilidad que los pacientes descritos con este sindrome de miositis focal post infección viral esté experimentado por primera vez una infección con el virus de la influenza, por los resultados negativos de anticuerpos séricos en la fase aguda. La ocurrencia de este sindrome principalmente en niños, sugiere igualmente que este tipo de miositis focal, haya sido contraída luego de una infección primaria con el virus de influenza B (11).

\section{REFERENCIAS BIBLIOGRAFICAS}

1. Middleton PJ, Alexander RM, Szymanski MT. Severe myositis during recovery from influenza. Lancet 1970; 2: 533-35.

2. Arregui A. Miositis aguda transitoria durante enfermedad viral tipo influenza. Rev Neuropsiquiat (Lima) 1986; 49: 188-91.

3. Hassell AB, Plant MJ, Dawes PT. Focal myositis: another cause of pseudothrombophlebitis (letter). Br J Rheumatol 1994; 33: 687. 
4. Toti P, Catella AM, Benvenuti A. Focal myositis a pseudotumoral lesion. Histopathology 1994; 24: 171-3.

5. Colding J E, Laursen H, Lauritzen M. Focal myositis of the thigh: report of two cases. Acta Neurol Scand 1993; 88: 289-92.

6. Flaisler F, Blin D, Asencia G, López FM, Combe B. Focal myositis: a localized form of polymyositis?. J Rheumatol 1993; 20: 1414-6.

7. Nagar H, Bar Ziv Y. Focal eosihophilic myositis. Unusual cause of a tumor on the chest wall. Eur J Surg 1993; 159: 187-8.

8. Lim KL, Robson K, Powell RJ. Focal myositis: an unusual cause of bilateral upper eyelid swellings. Postgrad Med J 1993; 69: 876-8.

9. Naumann M, Focal myositis of the temporal muscle. Muscle Nerve 1993; 16: 1374-6.

10. Isaacson G, Chan KH, Heffner RR Jr. Focal myositis. A new cause for the pediatric neck mass. Arch Otolaryngol Head Neck Surg 1991; 177: 103-5.

11. Dietzman DE, Schaller JG, Ray CG, Reed ME. Acute myositis associated with influenza B Infection. Pediatrics 1976; 57: 255-58.

12. Mason W. Acute transient myositis with influenza - like illness (letter) J Pediatrics 1975; 86: 813-14.

13. Mejlszenkier JD, Safran AP, Healy JJ, Embree L, Ouellette EM. The myositis of influenza. Arch Neurol 1973; 29: 441-3.

14. Lundberg A. Myalgia cruris epidemia. Acta Paediatric 1957; 46: 18.

15. Haddad MG. West RL, Treadwell EL. Fraser DD. Diagnosis with demonstration of the focal nature of myositis. Am J Clin Pathol 1994; 101: 661-4.

16. Henry JB. Editor. Clinical diagnosis and management by laboratory methods. Philadelphia: WB Saunders; 1969.p. 738.

17. Oseashon R, Adelson L, Kaji M. Clinicopathologic study of thirty three fatal cases of asian influenza. N Engl J Med 1959; 260-509.

\section{Correspondencia:}

Carlos Tori Tori

Centro Médico San Felipe. Av. Gregorio Escobedo 660.

Jesús María.

Lima, Perú. 